\title{
The Genetic-Determination of Ossification Sequence Polymorphism '
}

\author{
KEITH P. HERTZOG, ${ }^{2}$ FRANK FALKNER ${ }^{3}$ AND STANLEY M. GARN \\ The Fels Research Institute, Yellow Springs, Ohio, The Department of \\ Pediatrics, University of Louisville School of Medicine, Louisville, \\ Kentucky, and The Center for Human Growth and Development, \\ University of Michigan, Ann Arbor, Michigan
}

\begin{abstract}
Serial hand-wrist x-rays of 81 pairs of twins were examined to investigate the genetics of ossification sequence polymorphism. Discordance in ossification sequence was 3.5 times more common between like-sex dizygotic twins than between monozygotic twins, with the difference being significant at the 0.01 level of canfidence. These findings support the contention that the major part of variation in ossification sequence is genetically determined.
\end{abstract}

'The importance of ossification sequence polymorphism, which has recently been given increased attention (cf. Garn, Rohmann and Blumenthal, '66), depends in part on the causative mechanisms involved. Pryor ('07), in a study of carpal sequence variation in sibships, was the first to suggest that variation in the order of the radiographic appearance of secondary ossification centers is genetically-determined. Reynolds ('43), also examining the carpal sequence variation which is so common in white populations (Garn and Rohmann, '60), showed that identical twins had the highest concordance in sequence, followed by siblings, first cousins, and finally unrelated pairs of children. Additionally, atypical ossification sequences - such as the triquetral appearing prior to any phalangeal or metacarpal epiphysis, or the navicular, greater multangular and lesser multangular appearing so late that one or all of these may follow the distal ulnar epiphysis - have been traced through two generations (Garn and Rohmann, '62; Garn, Rohmann and Davis, '63). This type of evidence has led Garn ('62) to conclude that a major part of the variance in ossification order appears to be gene-determined.

In order to elucidate the genetics of sequence polymorphism, the serial handwrist $x$-rays of the monozygotic and likesex dizygotic white twins of group 1 of the Louisville Twin Study were examined. Zygosity was ascertained by both blood- grouping and placental evidence. X-rays for this group were taken at regular age intervals, from one month, for varying periods of up to 5.0 years of age. If sequence variation is gene-determined to a great extent, there should be fewer differences in sequence between monozygotic twins than between like-sex dizygotic twins. Accordingly, sequence variation was investigated by comparing the $x$-rays of a pair of twins at the same age. Discordance in sequence was recorded if one twin had center $a$ present, but center $b$ absent, while the other twin had center $a$ absent, but center $b$ present at the same age, and where $a$ and $b$ could represent any carpal or epiphyseal center. Only pairs of x-rays in which both twins had more than two and less than 28 centers, and in which all epiphyseal and carpal sites were clearly visible, were included in the study sample.

The final sample consisted of 81 pairs of twins, constituting 37 monozygotic pairs ( 14 male and 23 female) and 44 dizygotic pairs (20 male and 24 female). Each twin pair was represented at from one to five ages at which a pair of x-rays with the requisite number of centers was available. In all, the sample was composed of 209 pairs of x-rays, 100 representing monozygotic and 109 dizygotic twin pairings.

1 Supported, in part, by USPHS grants AM-03816, 2-F1-GM-28578, HD00482-06 and DE-01294.

2 Present address: Department of Anthropology, University of Pennsylvania.

3 Present address: Perinatal Biology and Infant Mortality Branch, National Institute of child Health and Human Development. 

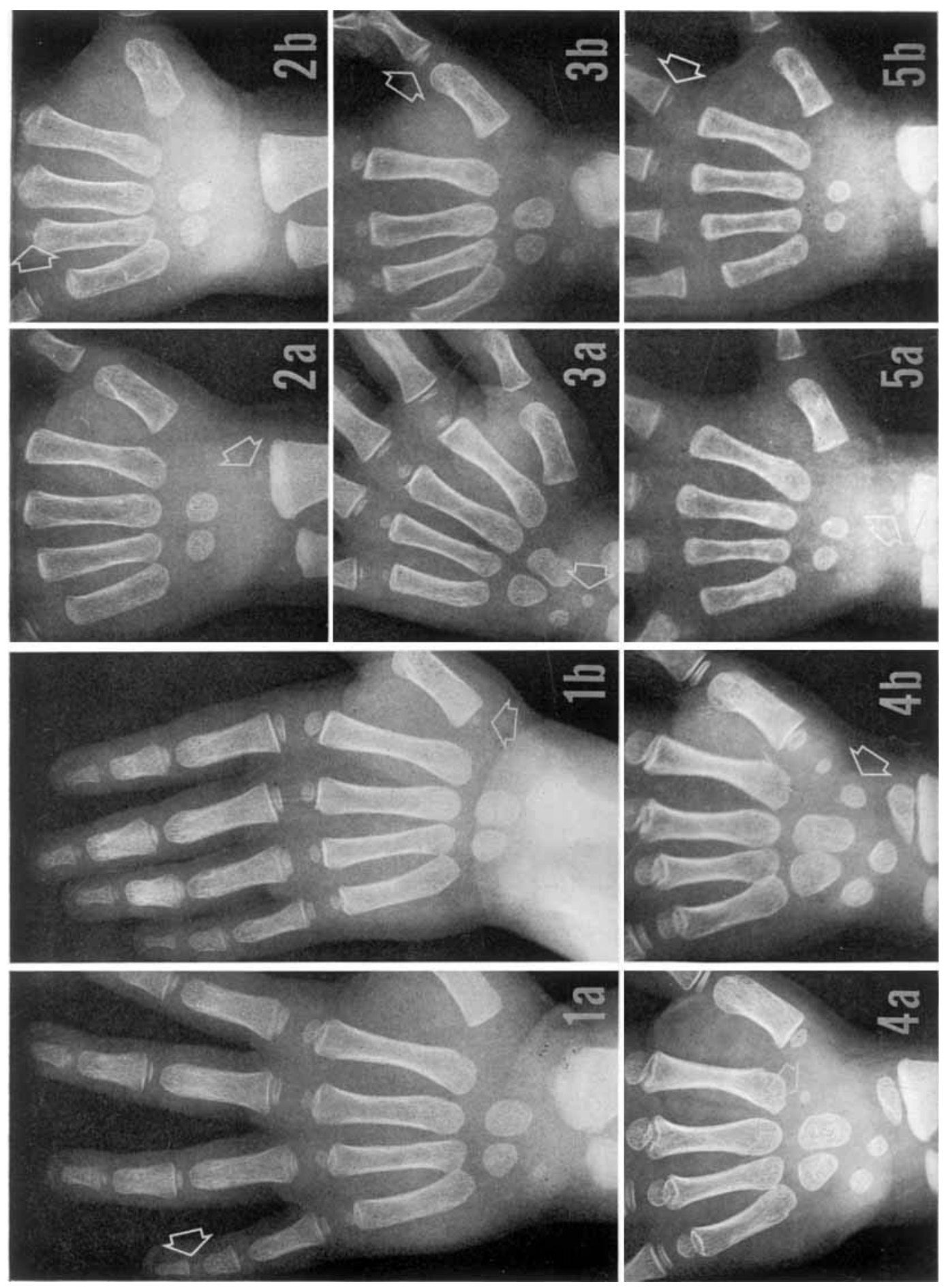
There was no difference between the monozygotic and dizygotic subsamples, either in the sex or age distribution of the number of pairs of x-rays.

Of the total of 209 pairings, 24 pairs of $\mathrm{x}$-rays, 5 pairs representing monozygotic twins and 19 pairs representing dizygotic twins, exhibited ossification sequence discordance (table 1). Three of the pairs of

TABLE 1

Twin concordance and discordance in hand-wrist ossification sequence

\begin{tabular}{lccc}
\hline $\begin{array}{c}\text { Zygosity of } \\
\text { twin pairs }\end{array}$ & \multicolumn{3}{c}{ Pairs of radiographs } \\
\cline { 2 - 4 } & $\begin{array}{c}\text { Discordant } \\
\text { no. }\end{array}$ & $\begin{array}{c}\text { Concordant } \\
\text { no. }\end{array}$ & $\begin{array}{c}\text { Total } \\
\text { no. }\end{array}$ \\
\hline Monozygotic ${ }^{1}$ & 5 & 95 & 100 \\
Dizygotic $^{1}$ & 19 & 90 & 109 \\
\hline
\end{tabular}

1 Difference between monozygotic and dizygotic twin concordance significant at $p=0.01$ or better, by chisquared test with or without corrections for continuity $\left(x^{2}=6.753\right.$, with Yates correction).

$\mathrm{x}$-rays represented a second and different polymorphism discordance for three pairs of twins. Accordingly the 24 pairs of discordant x-rays represented 21 pairs of twins. Each of the combinations of centers involved in a discordance was represented only once among the 24 cases of discordant sequence. No particular center or groups of centers was disproportionately represented. Figure 1 illustrates several examples of sequence discordance.

Fig. 1 Examples of discordance in handwrist ossification sequence in five pairs of twins. Sequence discordance shown between the epiphyses of the fifth distal phalanx and the first metacarpal in twin pair I-34 (1a, 1b), the epiphyses of the distal radius and the fourth metacarpal in twin pair I-57 (2a, 2b), the lunate and the epiphysis of the first proximal phalanx in twin pair I-38 (3a, 3b), the lesser multangular and the navicular and greater multangular in twin pair II-12 (4a, 4b), and the epiphyses of the distal radius and second proximal phalanx in twin pair $I-42(5 a, 5 b)$.
Inasmuch as there was no sex difference in the incidence of discordant pairs of $x$-rays $\left(x^{2}=0.003, p>0.95\right)$, data for both sexes and all ages were pooled and arranged in a $2 \times 2$ contingency table on the basis of both zygosity and concordance, and a chi-squared value was calculated. Discordance in ossification sequence was significantly greater between dizygotic twins than between monozygotic twins $\left(x^{2}\right.$, corrected for continuity, $=6.753, \mathrm{p}<$ 0.01 ). In all, discordances were 3.5 times more common between dizygotic twins than between monozygotic twins, and this figure provides a rough measure of heritability. Thus, while monozygotic twins are not completely concordant with respect to sequence of appearance of post-natal ossification centers, this twin study shows that the major part of variation in handwrist ossification sequence is genetically determined.

\section{LITERATURE CITED}

Garn, S. M. 1962 The genetics of normal human growth. In: De Genetica Medica, L. Gedda, ed., vol. 2, Gregor Mendel Institute, Rome, pp. 415-434,

Garn, S. M., and C. G, Rohmann 1960 Variability in the order of ossification of the bony centers of the hand and wrist. Am. J. Phys. Anthrop., 18: 219-230.

- 1962 Parent-child similarities in handwrist ossification. Am. J. Dis. Child., 103: 603607.

Garn, S. M., C. G. Rohmann and T. Blumenthal 1966 Ossification sequence polymorphism and sexual dimorphism in skeletal development. Am. J. Phys. Anthrop., 24: 101-115.

Garn, S. M., C. G. Rohmann and A. A. Davis 1963 Genetics of hand-wrist ossification. Am. J. Phys. Anthrop., 21: 33-40.

Pryor, J. W. 1907 The hereditary nature of variation in the ossification of bones. Anat. Rec., 1: 84-88.

Reynolds, E. L. 1943 Degree of kinship and pattern of ossification. Am. J. Phys. Anthrop., 1: 405-416. 